\title{
Curso Pensando Irán: Historia, Arte y Cultura
}

\section{Thinking Iran: History, Arts and Culture}

\author{
Leonardo René Millán Valencia \\ Programa Universitario de Estudios sobre África y Asia \\ Universidad Nacional Autónoma de México \\ millanvalencialeonardo@politicas.unam.mx
}

La relevancia de estudiar Irán en la actualidad va más allá de la coyuntura política, los conflictos y las tensiones entre Occidente y el gobierno de la República Islámica. La civilización irania es una de las más antiguas, importantes e influyentes de la historia universal. Los imperios persas siempre han estado presentes en las dinámicas y configuraciones de las coyunturas históricas, ya sea como archirrival de las civilizaciones grecolatinas o como modelo y aspiración cultural de los conquistadores árabes, turcos y mongoles.

En el curso "Pensando Irán: Historia, Arte y Cultura" se buscó consolidar un marco de estudio para la nación irania a partir de un enfoque multidimensional que abarque tanto la parte histórica como los temas de actualidad en los aspectos político, social, cultural y artístico. Se intentó construir entre los asistentes una sólida base que les permita acercarse al estudiode Iránalejados delos estereotipos y esquemas mentales orientalistas, haciendo énfasis en el carácter multicultural, multiétnico y socialmente diverso de la sociedad iraní.

Para efectos de pedagogía, la actividad se ha dividido en tres módulos temáticos: historia y política, filosofía, religión y literatura y, finalmente, arte y cultura. En el primero de ellos, se estudió una trayectoria histórica que abarca desde los primeros imperios que construyeron la identidad persa, los conquistadores extranjeros, la adaptación de la civilización irania a la ocupación y la configuración de la nación frente a la modernidad, para, finalmente, hacer un recuento de los sucesos más recientes 
que abarcan la revolución de 1979, la guerra contra Iraq y las dinámicas sociales y políticas de los años noventa y los albores del siglo XXI.

En el segundo módulo se enfatizó la riqueza del pensamiento iraní tanto clásico como contemporáneo. Se hizo un recorrido por las diversas religiones iranias que constituyen el marco de pensamiento y la cosmovisión de Irán, como el zoroastrismo y el maniqueísmo, credos íntegramente persas de cuya influencia ha dado cuenta el mundo occidental. También se estudiaron las interacciones entre el Islam y Persia, particularmente en la narrativa chiita y su diferencia con la ortodoxia musulmana, el sufismo como camino místico y espiritual, así como la filosofía de los grandes pensadores del Islam clásico como Ibn Sina y sus aportaciones a la religión, el derecho y la identidad islámica. La literatura para los pueblos iranios ha sido uno de los instrumentos más importantes en la conservación de la identidad persa. Prueba de ello es la relevancia del Shahnamé de Ferdousí, la gran épica de Irán y cuyo carácter de orgullo nacional lo sitúa como una joya de la literatura universal. De la misma manera, se estudió el papel de la poesía como componente clave de la expresión artística de Irán y una parte esencial de la identidad iraní, tanto en su parte clásica, como en el ámbito contemporáneo.
Finalmente, el curso concluyó con el módulo de arte y cultura que tuvo como objetivo difundir la forma en que los iraníes comprenden su mundo y cómo las expresiones artísticas se encuentran en una constante evolución en búsqueda de apelar a los más nobles sentimientos. Durante las diversas sesiones del módulo se abarcaron las artes plásticas, el dibujo tradicional, la caligrafía, la cerámica, la música, el teatro y el cine. Cabe destacar que a lo largo de toda esta actividad, se contó con proyecciones cinematográficas con el fin de ejemplificar mediante el séptimo arte los temas vistos durante las distintas ponencias.

El curso, que se realizó del 8 de agosto al 21 de noviembre de 2018 , en las instalaciones de la Casa de las Humanidades tuvo el privilegio de contar con los más destacados especialistas mexicanos e iraníes, quienes desde su área de estudio impartieron una maravillosa cátedra que sin duda, transformó entre los asistentes su manera de entender a Irán. Cabe destacar el aporte de la doctora Shekoufeh Mohammadi, coordinadora académica del curso y ponente de varias sesiones, sin cuyo ánimo, esfuerzo y pasión hubiera sido imposible la materialización de este curso.

Este gran esfuerzo requirió de la cooperación de diversas instituciones de la Universidad Nacional Autónoma de México, como el Programa 
Universitario de Estudios sobre Áfri- Leonardo René Millán Valencia ca y Asia, el Instituto de Investigacio- $\quad$ Egresado de la licenciatura en Relanes Filológicas, el Centro Universita- ciones Internacionales por la Faculrio de Estudios Cinematográficos y la tad de Ciencias Políticas y Sociales de Casa de las Humanidades. Ha permila UNAM, donde también ha fungido tido acercar a México a las dinámicas como adjunto en diversas asignaturas. de otras naciones, fomentando así Actualmente colabora en la Secretaría los vínculos entre ambas sociedades y ampliando los panoramas mentales de la sociedad mexicana. Académica del Programa Universitario de Estudios sobre África y Asia de la UNAM. 